\title{
Herramientas para la participación ciudadana virtual y su desarrollo en las webs del Sistema Sanitario Público de Andalucía
}

\author{
Manuel-Ángel Calvo-Calvo* \\ *Hospital Universitario Virgen del Rocío. Sevilla. Departamento de Enfermería. \\ Facultad de Enfermería, Fisioterapia y Podología. Universidad de Sevilla. \\ Correo electrónico: macalvo@us.es
}

Recibido: 13-11-2015; 2a versión: 21-02-2016; Aceptado: 25-02-2016.

Cómo citar este artículo/Citation: Calvo-Calvo, M. A. (2016). Herramientas para la participación ciudadana virtual y su desarrollo en las webs del Sistema Sanitario Público de Andalucía. Revista Española de Documentación Científica, 39 (4): e152. doi: http://dx.doi.org/10.3989/redc.2016.4.1349

Resumen: Los objetivos del estudio fueron identificar herramientas web para materializar la participación virtual ciudadana en salud, averiguar cuales de esas herramientas existen y su grado de desarrollo en las webs del Sistema Sanitario Público de Andalucía. Se identificaron 42 herramientas webs que pueden favorecer la información e interactividad con la ciudadanía y se realizó un estudio descriptivo y transversal, para averiguar qué herramientas participativas aparecen en seis webs del Sistema Sanitario Público de Andalucía. De las herramientas propuestas, 33 estaban presentes en las webs analizadas. La presencia en redes sociales y las aplicaciones Web 2.0 y 1.0 para la información de la ciudadanía, fueron los recursos participativos más desarrollados. Las herramientas 2.0 para la interacción web-usuarios y para la publicación de contenidos creados por los usuarios tuvieron un bajo grado de desarrollo. En las webs estudiadas no se desarrollaron aplicaciones on line para la interacción y colaboración entre usuarios.

Palabras clave: Web 2.0; Internet; virtual; sitios webs; participación ciudadana; salud; sistema sanitario público; Andalucía.

Tools for virtual citizen participation and its development in the websites of the Andalusia Public Health System

\begin{abstract}
The objectives of the study were to identify web tools leading to virtual citizen participation in health, to find out what tools exist and their degree of development in the websites of the Andalusia Public Health System. It identified 42 website tools that can facilitate information for, and interactivity with, citizenry. A descriptive and transversal study was then conducted to find out what participatory tools appear on six websites of the Andalusia Public Health System. Of the tools proposed, 33 were present in the analyzed webs. The participatory resources that were most developed by the organizations studied were the presence in social networks and Web 2.0 and 1.0 applications for informing the citizenry. 2.0 tools for web-user interaction and publishing contents created by users were developed to a lesser degree. Finally, online applications for interaction and collaboration among users had not been developed on the websites studied.
\end{abstract}

Keywords: Web 2.0; Internet; virtual; websites; citizen participation; health; public health system; Andalusia.

Copyright: (C) 2016 CSIC. Este es un artículo de acceso abierto distribuido bajo los términos de la licencia Creative Commons Attribution (CC BY) España 3.0. 


\section{INTRODUCCIÓN}

En los últimos años hemos asistido a una expansión revolucionaria de las tecnologías de la información y de la comunicación (TIC), lideradas por Internet, y que han resultado ser factores responsables de un gran cambio social. Debido a la universalización de estos nuevos recursos, cada vez más personas usan Internet para difundir, interactuar e involucrarse en posiciones y prácticas, lo que ha posibilitado una nueva forma de participación social en un nuevo contexto on line. La transformación surgida en el ámbito de la participación política gracias a las TIC, podría ser un buen ejemplo de este cambio social producido (Novo y Vicente, 2014).

El ámbito sanitario no ha quedado al margen de esta expansión de las TIC, pues los sistemas de atención sanitaria incorporan estas nuevas tecnologías a los procesos asistenciales para ofrecer servicios de salud tecnológicamente avanzados. Paralelamente, las TIC están favoreciendo el acceso de la ciudadanía a una mejor información sobre salud, por lo que surgen "nuevos" pacientes y ciudadanos con un mayor conocimiento sobre salud, y más capacitados para participar en los procesos individuales y colectivos de salud. Todo esto puede favorecer la transición desde el actual paciente casi "invisible e ignorado" por el sistema de salud, hacia un paciente "experto", informado y formado (Navarro, 2014). Esta nueva situación también obligará a un cambio cultural en la relación entre los sistemas sanitarios y pacientes, que puede facilitar el paso de un modelo "paternalista" de asistencia sanitaria hacia otro más deliberativo y participativo (Navarro, 2014; Jovell y Navarro, 2008).

En gran medida, estos nuevos planteamientos participativos están favorecidos por las aspiraciones de nuestra ciudadanía, que realmente demanda una mayor participación en asuntos públicos. Concretamente, el $91,5 \%$ de los españoles considera necesaria la participación de los ciudadanos en los asuntos públicos y más de la mitad de la población $(58,6 \%)$ considera que los canales que existen actualmente para la participación pública de la ciudadanía son insuficientes (Márquez y otros, 2013).

La "intervención de los particulares en actividades públicas, mediante el ejercicio de sus derechos civiles" (Segura, 2010), está amparado por la Constitución española. Igualmente, el derecho a la participación ciudadana en el ámbito sanitario también se recoge ampliamente en nuestro marco jurídico. Esto ha posibilitado experiencias en diversas comunidades autónomas que han tratado de incorporar la perspectiva del ciudadano a la asistencia sanitaria pública, mediante el desarrollo de planes de participación en sus centros sanitarios (Martín y otros, 2013). Estas experiencias también se han implementado en países como Italia, Portugal o Polonia (Serapioni y Matos, 2014; Kolasa y otros, 2014), lo cual indica que la participación ciudadana, para conformar "espacios públicos de participación y control social en torno a las políticas públicas de salud" (Santana y otros, 2014), es un objetivo emergente.

Las actuales experiencias participativas, en el ámbito sanitario, se han desarrollado mediante la participación presencial de los ciudadanos en comisiones de participación, la participación off line con encuestas o buzones de sugerencias, y la participación on line a través de los medios basados en las TIC e Internet (Martín y otros, 2013). No obstante, parece que las TIC se han usado, sobre todo, para facilitar información de salud en las webs, con el objetivo de impulsar la participación ciudadana en la toma de decisiones y en los cuidados de personas con enfermedades crónicas de gran impacto, como el cáncer de mama, la depresión o la diabetes. De ello son buenos ejemplos la plataforma web "PyDEsalud.com", promovida por el Sistema Nacional de Salud en España (Perestelo-Pérez y otros, 2013), o el Portal "Onconocimiento", auspiciado por la Consejería de Salud de Andalucía.

Además de proveer información, los actuales recursos on line permiten emplear nuevos medios y desarrollar formas virtuales de participación ciudadana individual y colectiva en asuntos de salud. Estos nuevos recursos Web 2.0, además de favorecer una mayor participación ciudadana pública son también una demanda social. Concretamente, el $81,4 \%$ de los españoles solicita nuevos canales de participación ciudadana, donde convivan los nuevos medios derivados de Internet y las TIC con los medios tradicionales. Para gestionar esas expectativas sociales de participación pública, la ciudadanía pide que se mejoren las herramientas de las webs gubernamentales $(71 \%)$, aumentar la presencia en redes sociales como Facebook o Twitter $(34 \%)$, proporcionar información personalizada en dispositivos móviles (32\%) o crear foros y comunidades on line (52\%) (Márquez y otros, 2013).

La percepción de la ciudadanía sobre las ventajas de los recursos on line, y más concretamente de la Web 2.0, es acertada, pues crean "espacios virtuales de interacción" entre personas y "servicios web basados en la inteligencia colectiva y la participación social". Estas enormes potencialidades hacen que la Web 2.0 fomente "la participación colectiva y gratuita basada en tecnologías abiertas, flexibles y fáciles de utilizar" por la ciudadanía (Tejada, 2012). No obstante, la "eParticipación" o aplicación de esos nuevos medios en los procesos de 
participación pública ciudadana (Salvador-Benítez y Gutiérrez-David, 2010), no implica crear un nuevo tipo de participación si no simplemente posibilitar más y mejor la participación de la ciudadanía (Casacuberta y Gutiérrez-Rubí, 2010).

Esos recursos Web 2.0, también pueden satisfacer las expectativas de participación social en salud. En el caso de España, los diferentes sistemas públicos autonómicos de salud gestionan la asistencia sanitaria a la ciudadanía en sus respectivos ámbitos territoriales, por lo que sus webs corporativas deben ser elementos fundamentales para promover la participación ciudadana virtual en asuntos de salud. La razón es que las webs son medios desarrollados en Internet, con potenciales características derivadas de su adaptación a la Web 2.0., por lo que pueden posibilitar una mayor participación activa y colaborativa de los usuarios de los sistemas sanitarios (Ruiz y otros, 2012).

Existen diversos estudios sobre las herramientas que materializan la participación ciudadana on line en ámbitos como la política (Karkin, 2013; Novo y Vicente, 2014), la enseñanza (Tejada, 2012), en ayuntamientos (Moreno, 2013), en ciberdiarios (Tejedor-Calvo, 2010), e incluso en diarios deportivos (Díaz-Campo, 2014). Sin embargo, no se han encontrado estudios que identifiquen aplicaciones que pueden implementarse en las webs para favorecer la participación ciudadana virtual en salud, aunque sí hay descritas experiencias puntuales que combinan la participación virtual y la presencial (Martín y otros, 2013).

En definitiva, se desconocen las herramientas que materializan la participación ciudadana en salud a través de las webs de las organizaciones sanitarias. En este ámbito se sabe que los grandes hospitales españoles, dependientes mayoritariamente de los sistemas sanitarios autonómicos, poseen webs deficitarias en herramientas de interactividad e interrelación con sus usuarios, y que esos hospitales están poco presentes en los nuevos medios sociales. Por tanto, las webs de hospitales públicos apenas facilitan la interacción y la relación con sus usuarios (Calvo-Calvo, 2014), por lo que tampoco promueven convenientemente la participación virtual de los ciudadanos en salud.

Ante este desconocimiento se planteó una investigación con los objetivos de identificar y proponer herramientas y contenidos, que a través de las webs puedan materializar la participación virtual de la ciudadanía en asuntos de salud, así como averiguar cuál de esas herramientas participativas existen y cuál es su grado de desarrollo, en las principales webs corporativas del Sistema Sanitario Público de Andalucía.
Creemos que el propósito de este trabajo tiene entidad suficiente como para constituir un objeto de estudio específico, dado que permitirá conocer las herramientas web, que complementando a los actuales canales presenciales de participación ciudadana en salud, pueden contribuir a una mayor y mejor participación pública en asuntos de salud. Igualmente, los resultados de este trabajo podrán ser usados como instrumento o modelo para evaluar el grado en que las organizaciones y los sistemas públicos de salud incorporan en sus websites las diferentes herramientas virtuales, que materializan la participación virtual ciudadana en asuntos de salud.

También parece relevante conocer las herramientas web implementadas en el Sistema Sanitario Público de Andalucía (SSPA), dado que además de las iniciativas que ha desarrollado para la intervención de la ciudadanía en asuntos de salud, es el sistema autonómico español que gestiona la asistencia sanitaria pública para un mayor número de ciudadanos, concretamente para más de 8.401 .000 andaluces (Instituto Nacional de Estadística, 2015).

\section{METODOLOGÍA}

Para responder al objeto de esta investigación se realizó un estudio en dos fases consecutivas durante los meses de septiembre a noviembre de 2015. En una primera fase se identificaron y propusieron las herramientas web, tanto 1.0 como 2.0 , que pueden materializar la participación virtual de la ciudadanía en asuntos de salud. La revisión de la literatura publicada al respecto sirvió para identificar dichas herramientas, dado que ningún estudio previo había establecido las aplicaciones que específicamente favorecen la participación virtual ciudadana en asuntos de salud.

Así, inicialmente se partió del estudio de Rodríguez-Martínez y otros (2012), que consta de 36 herramientas Web 2.0, para evaluar la interactividad y la participación en las webs de los periódicos on line (Díaz-Campo, 2014). Al ser un modelo propuesto para evaluar específicamente a cibermedios, de sus 36 aplicaciones se seleccionaron las herramientas adecuadas para este estudio, siguiendo dos criterios. Primero se excluyeron aquellas herramientas web, cuyas aportaciones consideramos que no eran relevantes o aplicables para desarrollar la participación ciudadana a través de las webs de organizaciones sanitarias. En segundo lugar, las herramientas no excluidas se seleccionaron definitivamente para el estudio, cuando también otros autores coincidían en considerarlas favorecedoras de la interactividad entre las webs y sus públicos. 
Posteriormente, herramientas web que no aparecían en el estudio de Rodríguez-Martínez y otros (2012), se incluyeron para esta investigación cuando otros autores las proponían para posibilitar la interacción entre webs y usuarios, y si considerábamos que eran herramientas relevantes o aplicables para desarrollar la participación ciudadana en el ámbito de la salud. Una vez establecidas las aplicaciones que materializaban la participación social en salud, estas se clasificaron en parámetros, que recogían los ámbitos de participación ciudadana virtual en salud. Dichos ámbitos son: el desarrollo de contenidos para la información, educación y promoción de la salud de la ciudadanía; la interacción con el ciudadano, la participación activa y la toma de decisiones por los usuarios (Martín y otros, 2013).

En la segunda fase de esta investigación, se trató de averiguar qué herramientas participativas identificadas anteriormente existían en las principales webs corporativas de los organismos del SSPA. Para identificar dichas webs, se analizó el website de la Consejería de Salud de la Junta de Andalucía (CS), dado que es el órgano responsable del sistema público de salud en Andalucía. De las webs del SSPA identificadas, se decidió excluir para este estudio aquellas webs que correspondían a organismos cuyas competencias y ámbito de actuación no estaban relacionadas directamente con la ciudadanía, tales como la Fundación IAVANTE, dedicada a la formación y evaluación de competencias profesionales, o la Agencia de Evaluación de Tecnologías Sanitarias de Andalucía. Por el contrario, se incluyeron en este trabajo las webs de los organismos del SSPA que tiene competencias y relación directa con la ciudadanía, pues se consideró que son organismos que deben materializar la participación ciudadana en el SSPA. AI aplicar estos criterios, en este trabajo se decidió analizar la presencia de herramientas participativas en las webs de la CS, del Servicio Andaluz de Salud (SAS), de la Escuela Andaluza de Salud Pública (EASP), de la Escuela de Pacientes (EP), de la Red Salud Andalucía (RSA) y de la Agencia de Calidad Sanitaria de Andalucía (ACSA).

Posteriormente se averiguó cuál de las herramientas participativas, que se identificaron en la primera fase de este trabajo, estaban presentes en esas seis webs del SSPA. Para ello, se analizó el contenido de las webs seleccionadas, mediante un estudio observacional, descriptivo, de corte transversal, realizado entre los días 18 y 20 de octubre de 2015. El autor del trabajo analizó todos los sitios web, para tratar de evitar la subjetividad y la variación intraoperador, por lo que no hubo necesidad de adoptar medidas contra fuentes potenciales de sesgo.
En esta investigación, las herramientas propuestas en la primera fase constituyeron las variables de estudio (Anexo I). Para evaluar dichas variables, se observó la ausencia o presencia de cada herramienta de participación ciudadana virtual, en las seis webs analizadas. La presencia de estas herramientas en las webs del SSPA, se cuantificó mediante el método propuesto por Díaz-Campo (2014), donde cada herramienta fue puntuada con cero o uno, correspondiendo respectivamente a la ausencia o presencia de cada herramienta en las diferentes webs.

A continuación, se averiguó la intensidad de la presencia o grado de desarrollo, que las herramientas de participación ciudadana en salud tenían en el conjunto de las webs del SSPA. Para ello, se sumaron las puntuaciones obtenidas por las herramientas de cada parámetro (Anexo I), en las seis webs estudiadas. Esta puntuación total o valor resultante de cada parámetro, se dividió por el número de herramientas contenidas en el parámetro correspondiente. El cociente resultante fue el grado del desarrollo de las herramientas participativas de cada parámetro, en las seis webs del SSPA.

En nuestro caso, ese grado de desarrollo obtenido por cada parámetro en las webs del SSPA, fue un valor comprendido entre cero y seis, y para calificar dicho desarrollo se estableció la siguiente escala: un valor "cero", indicaría un nulo desarrollo del parámetro en cuestión, en las webs estudiadas; los valores superiores a cero e inferiores a uno, significaban un muy bajo desarrollo del parámetro; valores superiores a uno e inferiores a dos, se consideraría un bajo desarrollo; valores superiores a dos e inferiores a cuatro, indicarían un desarrollo medio; y valores superiores a cuatro significaban un alto desarrollo del parámetro, en las webs del SSPA. El valor "seis" indicaría el máximo desarrollo de un parámetro.

\section{RESULTADOS}

\subsection{Herramientas web identificadas para ma- terializar la participación virtual ciudadana en salud}

De las 36 aplicaciones que consta el modelo de Rodríguez-Martínez y otros (2012), se seleccionaron 24 herramientas para nuestro estudio, dado que consideramos que sus aportaciones eran relevantes o aplicables para desarrollar la participación ciudadana a través de webs de organizaciones sanitarias, y porque también otros autores coincidían en señalar a esas herramientas como favorecedoras de la interactividad entre las webs y sus públicos (Tabla I). 
Tabla I. Herramientas web propuestas para materializar la participación ciudadana en salud

\begin{tabular}{|c|c|}
\hline Herramientas web seleccionadas* & $\begin{array}{l}\text { Otros autores que las } \\
\text { proponen** }\end{array}$ \\
\hline \multicolumn{2}{|l|}{ Parámetro 1. Interacción medio de comunicación-usuario } \\
\hline Comunicación con el autor de la noticia. & 1 \\
\hline Contacto con la redacción del medio de comunicación. & 1 \\
\hline Comentar noticias publicadas por el medio de comunicación. & $2,3,4$ \\
\hline Votación de noticias publicadas por el medio de comunicación. & 3 \\
\hline Comentar entradas publicadas en los blogs del medio de comunicación. & 3 \\
\hline El usuario puede modificar o corregir contenido publicado por el medio. & 5 \\
\hline \multicolumn{2}{|l|}{ Parámetro 2. Publicación de contenidos creados por los usuarios } \\
\hline Creación de blogs por los usuarios. & $2,3,4,5$ \\
\hline Publicación de textos escritos por los usuarios. & 2,3 \\
\hline Publicación de fotos tomadas por los usuarios. & 2,3 \\
\hline Publicación de vídeos realizados por los usuarios. & 2,3 \\
\hline Sección exclusiva para contenido creado por los usuarios. & 3,6 \\
\hline \multicolumn{2}{|l|}{ Parámetro 3. Registro del usuario } \\
\hline Registro por parte del usuario en el medio. & 1,2 \\
\hline Contacto con otros usuarios registrados. & 1,2 \\
\hline \multicolumn{2}{|l|}{ Parámetro 4. Acceso a la información } \\
\hline Acceso a la información a través de la recomendación de los usuarios. & 3 \\
\hline \multicolumn{2}{|l|}{ Parámetro 5. Personalización de la información } \\
\hline Sindicación de contenidos del medio de comunicación a través del móvil o correo electrónico. & $1,3,5,6$ \\
\hline Suscripción de alertas o boletín electrónico. & 3 \\
\hline \multicolumn{2}{|l|}{ Parámetro 6. Se ofrecen distintas versiones de la información } \\
\hline \multicolumn{2}{|l|}{ De este parámetro no se seleccionaron herramientas para este estudio. } \\
\hline \multicolumn{2}{|l|}{ Parámetro 7. Empleo de herramientas de la Web 2.0} \\
\hline Compartir información con otros usuarios. & 3 \\
\hline Blogs vinculados al medio de comunicación. & $1,3,6$ \\
\hline \multicolumn{2}{|l|}{ Parámetro 8. Presencia el medio de comunicación en plataformas de la Web 2.0} \\
\hline Presencia del medio de comunicación en plataformas audiovisuales. & $1,2,4,5,6,7$ \\
\hline Presencia del medio de comunicación en plataformas de imágenes. & $1,2,4,5,6,7$ \\
\hline Presencia del medio de comunicación en redes sociales profesionales externas. & $1,2,4,5,6,7$ \\
\hline Presencia del medio de comunicación en redes sociales de amistad. & $1,2,4,5,6,7,8$ \\
\hline Presencia del medio de comunicación en plataformas de microblogging. & $1,2,4,5,6$ \\
\hline Vinculación entre el sitio web del medio de comunicación y las plataformas sociales. & $1,2,4,5,6$ \\
\hline \multicolumn{2}{|c|}{$\begin{array}{l}\text { * } 24 \text { herramientas web seleccionadas del modelo de Rodríguez-Martínez y otros (2012). } \\
\text { **Estas } 24 \text { herramientas también han sido propuestas como aplicaciones para favorecer la participación ciudadana, por Ic } \\
\text { siguientes autores: }\end{array}$} \\
\hline \multicolumn{2}{|c|}{$\begin{array}{ll}\text { 1. Haanefa y Jasna (2014). } & \text { 5. Karkin (2013). } \\
\text { 2. Salvador-Benítez y Gutiérrez-David (2010). } & \text { 6. Tejedor-Calvo (2010). } \\
\text { 3. García-De-Torres (2010). } & \text { 7. Tejada (2012). } \\
\text { 4. Ihlebæk y Krumsvik (2015). } & \text { 8. Cmciu y Cmciu (2014). }\end{array}$} \\
\hline
\end{tabular}


Estas herramientas seleccionadas inicialmente pertenecían a la Web 2.0, y a siete de los ocho parámetros propuestos por Rodríguez-Martínez y otros (2012). De los cuatro parámetros "interacción medio de comunicación-usuario", "publicación de contenidos creados por los usuarios", "registro de usuario" y "empleo de herramientas Web 2.0", se seleccionaron todas sus herramientas. Del referido al "acceso a la información" se seleccionó sólo la herramienta "acceso a la información a través de la recomendación de los usuarios". Del parámetro "personalización de la información", se seleccionaron dos de sus tres herramientas: la "sindicación de contenidos" y la "suscripción de alertas o boletín electrónico"; y del parámetro "presencia en plataformas Web 2.0" se seleccionaron seis de sus siete herramientas (Tabla I).

Las doce herramientas restantes, del modelo de Rodríguez-Martínez y otros (2012), no fueron seleccionadas para nuestro trabajo, porque consideramos que sus aportaciones a la participación ciudadana no aportaban ventajas o no eran aplicables al ámbito de la salud. Así, se desecharon siete aplicaciones sobre acceso y personalización de la información, las cuatro herramientas del "parámetro 6", referido a la posibilidad de que las webs "ofrezcan distintas versiones de su información", y la herramienta "empleo de redes sociales propias".

Posteriormente, a las 24 herramientas seleccionadas inicialmente (Tabla I), se añadieron 18 que fueron propuestas por otros autores y porque considerábamos que eran herramientas relevantes o aplicables para desarrollar la participación ciudadana en salud (Tabla II). Estas 18 aplicaciones estaban relacionadas con las Webs 1.0 y 2.0 , y se incluyeron en el estudio porque también posibilitaban la interacción usuarios-webs, así como la relación virtual entre los propios usuarios.

Tabla II. Herramientas web para materializar la participación ciudadana en salud, propuestas por otros autores

\begin{tabular}{|c|c|}
\hline 1. Herramientas de contenidos Web 1.0 & Autores que las proponen* \\
\hline 1.1. Sección de "Participación ciudadana" & \multirow{4}{*}{1} \\
\hline 1.2. Información sobre el plan de participación ciudadana & \\
\hline 1.3. Agenda de actividades para la ciudadanía & \\
\hline 1.4. Enlaces a webs de entidades ciudadanas & \\
\hline 1.5. Información sobre listas de espera & \multirow{4}{*}{2} \\
\hline 1.6. Contenidos sobre información y promoción de la salud & \\
\hline 1.7. Sección de noticias de actualidad & \\
\hline 1.8. Publicación de resultados de la encuesta de satisfacción & \\
\hline \multicolumn{2}{|l|}{ 2. Contenidos y aplicaciones Web $\mathbf{2 . 0}$} \\
\hline 2.1. Podcasts & $3,4,5$ \\
\hline 2.2. Taggs o etiquetas sociales & $4,6,7$ \\
\hline 2.3. Presencia en redes sociales no señaladas por Rodríguez-Martínez y otros (2012) & 8 \\
\hline \multicolumn{2}{|l|}{ 3. Herramientas de interacción websites-usuarios } \\
\hline 3.1. Solicitud de información general y sobre los servicios del sistema sanitario & \multirow{4}{*}{2} \\
\hline 3.2. Espacio público para preguntas y respuestas de los ciudadanos & \\
\hline 3.3. Buzón electrónico de sugerencias. & \\
\hline 3.4. Posibilidad de pedir cita para consultas médicas a través de la web & \\
\hline 3.5. Consultas públicas a la ciudadanía sobre asuntos de salud de interés. & 4 \\
\hline \multicolumn{2}{|l|}{ 4. Aplicaciones para la interacción entre usuarios } \\
\hline 4.1. Aplicaciones participativas de debate & $3,4,9,10,11$ \\
\hline 4.2. Herramientas digitales colaborativas de participación online & $7,12,13$ \\
\hline \multicolumn{2}{|l|}{ * Autores que proponen estas herramientas para favorecer la participación ciudadana: } \\
\hline \multicolumn{2}{|l|}{$\begin{array}{l}\text { 1. Moreno y otros (2013). } \\
\text { 2. Calvo-Calvo (2014). } \\
\text { 3. Checa (2013). } \\
\text { 4. Tejedor-Calvo (2010). } \\
\text { 5. Haanefa y Jasna (2014). } \\
\text { 6. Pérez y otros (2014). } \\
\text { 7. Karkin (2013). }\end{array}$} \\
\hline
\end{tabular}


En consecuencia, en este estudio se identificaron un total de 42 herramientas web para materializar la participación virtual ciudadana en salud (Anexo I). Estas herramientas se agruparon en seis parámetros, en función de los diferentes ámbitos que deben desarrollarse para materializar la participación ciudadana en salud (Martín y otros, 2013). Esos seis parámetros fueron los siguientes: desarrollo de contenidos Web 1.0 para la información, educación y promoción de la salud de la ciudadanía; aplicaciones Web 2.0; herramientas de interacción web-usuarios; contenidos creados por los usuarios; presencia en plataformas Web 2.0; y aplicaciones on line para la interacción entre usuarios (Anexo I).

\subsection{Herramientas para materializar la parti- cipación ciudadana en las webs corporativas del Sistema Sanitario Público de Andalucía}

De las 42 herramientas propuestas en este trabajo para materializar la participación ciudadana virtual en salud, $33(78,6 \%)$ estaban presentes en alguna de las seis webs del SSPA y nueve herramientas $(21,4 \%)$ no se encontraron en las webs estudiadas (Anexo I). Esas 33 herramientas se han desarrollado un total de 80 veces, en las seis webs del SSPA.

La web del SSPA que más herramientas participativas implementó fue la de la EP con $23(67,65 \%)$, seguidas por la web de la CS, con 15 herramientas $(44,12 \%)$; la web del SAS, con $14(41,18 \%)$; la de
RSA, con 12 herramientas (35,29\%); la web de la EASP, con $9(26,47 \%)$; y la de la ACSA, con siete herramientas $(20,59 \%)$.

\section{Parámetro 1: Recursos Web 1.0 para la infor- mación, educación y promoción de la salud de la ciudadanía, en las webs del Sistema Sani- tario Público Andaluz}

Los ocho recursos 1.0, del "parámetro 1", estaban presentes en alguna de las seis webs del SSPA (Tabla III). Concretamente, esos ocho recursos se implementaron 17 veces en total, en las webs estudiadas, por lo que al desarrollo de este parámetro en el SSPA, le correspondió una puntuación de 2,1 (Tabla VIII). Esto indicaba un desarrollo medio de este parámetro, en las webs estudiadas. La web del SAS fue la que contenía un mayor número de recursos Web 1.0 (7), seguidas por las webs de la $C S$ y de la EP, con 4 recursos disponibles en cada una. Todas las webs, excepto la de RSA, disponían de sección de noticias de actualidad. Las websites de la CS, del SAS y de la EP tenían también contenidos de información y promoción de la salud. Sólo las webs de la CS y del SAS poseían una sección de participación ciudadana, así como enlaces a la Oficina Virtual del SSPA (InterSAS), para información sobre listas de espera. Sin embargo, únicamente la web del SAS informaba sobre el plan de participación ciudadana y publicaba resultados de encuestas de satisfacción de los usuarios.

Tabla III. Parámetro 1: Recursos Web 1.0, en las webs del Sistema Sanitario Público Andaluz, para favorecer la información, educación y promoción de la salud de la ciudadanía

\begin{tabular}{|c|c|c|c|c|c|c|c|}
\hline \multirow{2}{*}{ Recursos Web 1.0} & \multicolumn{6}{|c|}{ Websites } & \\
\hline & CS & SAS & EP & ACSA & RSA & EASP & \\
\hline 1. Sección de "Participación ciudadana" & & & & & & & 2 \\
\hline 2. Información sobre el plan de participación ciudadana & & & & & & & 1 \\
\hline 3. Agenda de actividades para la ciudadanía & & & & & & & 1 \\
\hline 4. Enlaces a webs de entidades ciudadanas & & & & & & & 2 \\
\hline 5. Información sobre listas de espera & & & & & & & 2 \\
\hline 6. Contenidos sobre información y promoción de la salud & & & & & & & 3 \\
\hline 7. Sección de noticias de actualidad & & & & & & & 5 \\
\hline 8. Publicación de resultados de la encuesta de satisfacción & & & & & & & 1 \\
\hline Total de recursos Web 1.0 , en las webs del SSPA & & & & & & & 17 \\
\hline
\end{tabular}


Parámetro 2: Aplicaciones Web 2.0 para la información, educación y promoción de la salud de la ciudadanía

Las siete aplicaciones Web 2.0 de este parámetro, se implementaron 16 veces, en las webs del SSPA (Tabla IV), por lo que al desarrollo de este parámetro en el SSPA, le correspondió una puntuación de 2,28 (Tabla VIII). Esto indicaba un desarrollo medio de este "parámetro 2", en las webs estudiadas. EI website que desarrolló más aplicaciones Web 2.0 para contenidos, fue el de la EP (5), seguida por la web del SAS (4) y la web de RSA, que desarrolló 3 aplicaciones. Las herramientas "Contenidos recomendados por los usuarios" y "Más popular", no estaban presentes en las webs del SSPA (Tabla IV).

\section{Parámetro 3: Herramientas de interacción web-usuarios}

Las 13 herramientas de este parámetro se implementaron 24 veces en total en las webs del SSPA (Tabla V). Por tanto, al desarrollo del "parámetro 3 " le correspondió una puntuación de 1,8 , lo que indicaba un desarrollo bajo de este parámetro en las webs estudiadas (Tabla VIII). La web que desarrolló más herramientas para interactuar con sus usuarios, fue la de la EP (7), seguida por la web de RSA (6) y las de la CS, del SAS y de la EASP, que desarrollaron 3 aplicaciones cada una. En las webs estudiadas no se implementó la posibilidad de que los usuarios modifiquen o corrijan los contenidos publicados, ni las consultas públicas a la ciudadanía en asuntos de salud de interés. Tampoco se implementó la posibilidad de que los usuarios registrados en un website puedan contactar y relacionarse entre ellos.

\section{Parámetro 4: Publicación de contenidos crea- dos por los usuarios}

En las webs del SSPA estaban presentes tres de las cinco herramientas que favorecían la publicación de contenidos creados por los usuarios. Esas herramientas fueron la creación de blogs, de textos escritos y de videos realizados por usuarios, y todas ellas se encontraban en la web de la EP (Tabla VI). Por tanto, al desarrollo del "parámetro 4" le correspondió un valor de 0,6, lo que indicó un desarrollo muy bajo de este parámetro, en las webs estudiadas (Tabla VIII). Así mismo, en las webs analizadas no había posibilidad de publicar fotos tomadas por los usuarios, ni en ellas existía una sección específica para publicar los contenidos creados por los usuarios (Tabla VI).

\section{Parámetro 5: Presencia en plataformas de la Web 2.0 o redes sociales}

Todos los organismos del SSPA, cuyas webs han sido estudiadas, excepto el SAS, estaban presentes en redes sociales que no se dedican exclusivamente a cuestiones de naturaleza sanitaria (Tabla VII). La CS es la que más espacios tiene en plataformas de la Web 2.0 (5). La EP y la EASP están presentes en tres redes sociales cada una, y la ACSA y RSA tienen espacios en dos redes sociales cada una. De los seis organismos del SSPA estudiados, cinco están presentes en Twitter, cuatro en Facebook, dos en SlideShare y uno en Flickr, Vimeo y YouTube (Tabla VII). Así mismo, no se encontraron enlaces de webs del SSPA a redes sociales profesionales. Las siete herramientas de este "parámetro 5" se implementaron un total de 20 veces en las webs del SSPA, por lo que al desarrollo de este parámetro le correspondió una puntuación de 2,86 (Tabla VIII). Esto indicó que, en las webs estudiadas, hubo un desarrollo medio de este parámetro.

Tabla IV. Parámetro 2: Aplicaciones Web 2.0 en las webs del Sistema Sanitario Público Andaluz, para favorecer la información, educación y promoción de la salud de la ciudadanía

\begin{tabular}{|c|c|c|c|c|c|c|c|}
\hline \multirow{2}{*}{ Aplicaciones Web 2.0} & \multicolumn{6}{|c|}{ Websites } & \\
\hline & CS & SAS & EP & ACSA & RSA & EASP & \\
\hline $\begin{array}{l}\text { 1. Contenidos recomendados por los usuarios ("Más } \\
\text { popular") }\end{array}$ & & & & & & & 0 \\
\hline $\begin{array}{l}\text { 2. Enlaces RSS (Servicios de sindicación de } \\
\text { contenidos) }\end{array}$ & & & & & & & 4 \\
\hline 3. Suscripción de alertas o boletín electrónico & & & & & & & 2 \\
\hline 4. Compartir información con otros usuarios & & & & & & & 4 \\
\hline $\begin{array}{l}\text { 5. Blogs vinculados a la web y creados por } \\
\text { profesionales del Sistema Sanitario }\end{array}$ & & & & & & & 1 \\
\hline 6. Videocasts & & & & & & & 3 \\
\hline 7. Tags o etiquetas sociales & & & & & & & 2 \\
\hline \multicolumn{7}{|l|}{ Total de aplicaciones Web 2.0, en las webs del SSPA } & 16 \\
\hline \multicolumn{8}{|c|}{$\begin{array}{l}\text { CS: Consejería de Salud de Andalucía. SAS: Servicio Andaluz de Salud; EP: Escuela de Pacientes; ACSA: Agencia de } \\
\text { Calidad Sanitaria de Andalucía; RSA: Red Salud Andalucía; EASP: Escuela Andaluza de Salud Pública. } \square=1 \quad \square=0\end{array}$} \\
\hline
\end{tabular}


Tabla V. Parámetro 3: Herramientas de interacción web-usuarios, del Sistema Sanitario Público de Andalucía

\begin{tabular}{|c|c|c|c|c|c|c|c|}
\hline \multirow{2}{*}{ Herramientas } & \multicolumn{7}{|c|}{ Websites } \\
\hline & CS & SAS & EP & ACSA & RSA & EASP & \\
\hline $\begin{array}{l}\text { 1. Comunicación con el autor de los contenidos de la } \\
\text { web }\end{array}$ & & & & & & & 2 \\
\hline $\begin{array}{l}\text { 2. Contacto con el administrador o responsable del } \\
\text { website }\end{array}$ & & & & & & & 5 \\
\hline 3. Comentar contenidos publicados en la web & & & & & & & 2 \\
\hline $\begin{array}{l}\text { 4. Comentar entradas publicadas en blogs vinculados } \\
\text { a la web }\end{array}$ & & & & & & & 1 \\
\hline $\begin{array}{l}\text { 5. Valoración de los usuarios sobre los contenidos del } \\
\text { website }\end{array}$ & & & & & & & 3 \\
\hline $\begin{array}{l}\text { 6. Modificación por los usuarios, del contenido } \\
\text { publicado en la web }\end{array}$ & & & & & & & 0 \\
\hline $\begin{array}{l}\text { 7. Solicitud de información general y sobre los } \\
\text { servicios del sistema sanitario }\end{array}$ & & & & & & & 2 \\
\hline $\begin{array}{l}\text { 8. Espacio público para preguntas y respuestas de } \\
\text { los ciudadanos }\end{array}$ & & & & & & & 1 \\
\hline 9. Buzón electrónico de sugerencias & & & & & & & 3 \\
\hline $\begin{array}{l}\text { 10. Consultas públicas a la ciudadanía sobre asuntos } \\
\text { de salud de interés }\end{array}$ & & & & & & & 0 \\
\hline $\begin{array}{l}\text { 11. Posibilidad de pedir cita para consultas médicas a } \\
\text { través de la web }\end{array}$ & & & & & & & 2 \\
\hline 12. Registro por parte del usuario en el website & & & & & & & 3 \\
\hline 13. Contacto con otros usuarios registrados & & & & & & & 0 \\
\hline Total de herramientas de interacción web-usuarios, en & s we & del SS & & & & & 24 \\
\hline
\end{tabular}

Tabla VI. Parámetro 4: Publicación de contenidos creados por los usuarios, en las webs del Sistema Sanitario Público Andaluz

\begin{tabular}{|c|c|c|c|c|c|c|c|}
\hline \multirow{2}{*}{ Herramientas } & \multicolumn{6}{|c|}{ Websites } & \\
\hline & CS & SAS & EP & ACSA & RSA & EASP & \\
\hline 1. Creación de blogs por usuarios del website & & & & & & & 1 \\
\hline 2. Publicación de textos escritos por los usuarios & & & & & & & 1 \\
\hline 3. Publicación de fotos tomadas por los usuarios & & & & & & & 0 \\
\hline 4. Publicación de vídeos realizados por los usuarios & & & & & & & 1 \\
\hline $\begin{array}{l}\text { 5. Publicación de contenidos de los usuarios, en } \\
\text { sección específica }\end{array}$ & & & & & & & 0 \\
\hline \multicolumn{7}{|c|}{ Total de recursos para publicar contenidos de usuarios, en las webs del SSPA } & 3 \\
\hline
\end{tabular}


Tabla VII. Parámetro 5: Presencia del Sistema Sanitario Público Andaluz en redes sociales

\begin{tabular}{|c|c|c|c|c|c|c|c|c|}
\hline \multirow{2}{*}{$\begin{array}{l}\text { Herramientas } \\
\text { CS }\end{array}$} & & \multicolumn{7}{|c|}{ Websites } \\
\hline & & \multirow[t]{2}{*}{ CS } & \multirow[t]{2}{*}{ SAS } & \multirow[t]{2}{*}{ EP } & \multirow[t]{2}{*}{ ACSA } & \multirow[t]{2}{*}{ RSA } & \multirow[t]{2}{*}{ EASP } & \\
\hline \multirow{2}{*}{$\begin{array}{l}\text { 1. Presencia en plataformas } \\
\text { audiovisuales }\end{array}$} & YouTube & & & & & & & 2 \\
\hline & Vimeo & & & & & & $*$ & 1 \\
\hline $\begin{array}{l}\text { 2. Presencia en plataformas de } \\
\text { imágenes }\end{array}$ & Flickr & & & & & & & 1 \\
\hline $\begin{array}{l}\text { 3. Presencia en redes sociales } \\
\text { profesionales externas }\end{array}$ & & & & & & & & 0 \\
\hline $\begin{array}{l}\text { 4. Presencia en redes sociales de } \\
\text { amistad }\end{array}$ & Facebook & & & & & & & 4 \\
\hline $\begin{array}{l}\text { 5. Presencia en plataformas } \\
\text { de microblogging }\end{array}$ & Twitter & & & & & & & 5 \\
\hline $\begin{array}{l}\text { 6. Otras redes sociales en las que } \\
\text { está presente el Sistema Sanitario }\end{array}$ & SlideShare & & & & & $*$ & & 2 \\
\hline \multicolumn{2}{|c|}{$\begin{array}{l}\text { 7. Enlaces entre el sitio web y las plataformas } \\
\text { sociales }\end{array}$} & & & & & & & 5 \\
\hline \multicolumn{8}{|c|}{ Total de presencia del SSPA, en redes sociales } & 20 \\
\hline \multicolumn{9}{|c|}{$\begin{array}{l}\text { CS: Consejería de Salud de Andalucía. SAS: Servicio Andaluz de Salud; EP: Escuela de Pacientes; ACSA: Agencia de Calidad Sanitaria } \\
\text { de Andalucía; RSA: Red Salud Andalucía; EASP: Escuela Andaluza de Salud Pública. } \square=1 \text { (Presencia) }\end{array}$} \\
\hline
\end{tabular}

Parámetro 6: Aplicaciones on line para la interacción entre usuarios

En las seis webs del SSPA no se identificaron aplicaciones participativas de debate, ni herramientas digitales colaborativas de participación on line. Por tanto, al desarrollo de este "parámetro 6", le correspondió cero puntos. Esto indicó un desarrollo nulo de dicho parámetro (Tabla VIII).

\section{DISCUSIÓN}

Los objetivos de esta investigación fueron identificar herramientas web que materialicen la participación virtual de la ciudadanía en asuntos de salud, y su desarrollo en las principales webs corporativas del SSPA. Según los resultados obtenidos se identificaron 42 herramientas web, por lo que se incrementaron e incorporaron nuevos recursos participativos, respecto a las 36 herramientas del modelo de Rodríguez-Martínez y otros (2012). Por tanto, pensamos que este estudio actualiza y completa dicho modelo.

Concretamente, este trabajo actualiza el modelo de Rodríguez-Martínez y otros (2012), porque incorpora nuevas aplicaciones Web 2.0 (Tabla II), necesarias para crear entornos más colaborativos y de participación social, y que favorecen el cambio de paradigma "en la interacción administración-ciudadanos" (Karkin, 2013). Además, en esta investigación se han incluido recursos Web 1.0, que completan el trabajo de Rodríguez-Martínez y otros (2012), dado que estos autores sólo incluyen herramientas Web 2.0. Estas aplicaciones 1.0 , que generan contenidos para informar, educar y promover la salud de la ciudadanía, aún son esenciales en el ámbito de la salud, pues "si no se provee información, no hay participación" efectiva (Karkin, 2013).

Dado que en las webs del SSPA existían casi un $80 \%$, de las herramientas participativas propuestas en este trabajo, se puede afirmar que se identificó una alta presencia de esas herramientas en el sistema sanitario andaluz. Esto denota la toma de conciencia y propósito de adaptación del SSPA a nuevos entornos virtuales, que propicien la participación ciudadana en salud. Además, con el alto empleo de esas herramientas participativas, el SSPA eleva el nivel de interacción con sus usuarios, dotando mejor a la ciudadanía para comportarse como actores colaborativos, en los asuntos de salud que les compete o en los cuales deciden participar.

Sin embargo, algo más del $20 \%$ de las herramientas de nuestro modelo no estaban presentes, en las webs del SSPA (Anexo I). Estas herramientas ausentes pertenecían a la Web 2.0 y posibilitan la publicación en webs de contenidos creados por la ciudadanía y la interacción entre los propios usuarios. Parece, por tanto, que en las webs estudiadas todavía primaban los contenidos 1.0 , creados 
Tabla VIII. Desarrollo de los parámetros de participación ciudadana virtual, en las webs del Sistema Sanitario Público Andaluz (SSPA)

\begin{tabular}{|l|c|c|c|c|}
\hline Parámetros & Valor & Herramientas & Desarrollo & $\begin{array}{c}\text { Grado de } \\
\text { desarrollo }\end{array}$ \\
\hline 1. Recursos Web 1.0 & 17 & 8 & 2,1 & Medio \\
\hline 2. Aplicaciones Web 2.0 & 16 & 7 & 2,28 & Medio \\
\hline 3. Herramientas de interacción web-usuarios & 24 & 13 & 1,8 & Bajo \\
\hline 4. Publicación de contenidos creados por los usuarios & 3 & 5 & 0,6 & Muy Bajo \\
\hline $\begin{array}{l}\text { 5. Presencia del Sistema Sanitario Público Andaluz en } \\
\text { redes sociales }\end{array}$ & 20 & 7 & 2,86 & Medio \\
\hline 6. Aplicaciones on line para la interacción entre usuarios & 0 & 2 & 0 & Nulo \\
\hline $\begin{array}{l}\text { Cálculo del "Desarrollo del parámetro"= valor/número } \\
\text { de herramientas }\end{array}$ & & & & \\
\hline
\end{tabular}

de "uno-para-muchos", aunque la tendencia actual sea la creación de contenidos 2.0, de "muchoscon-muchos" (Karkin, 2013). En consecuencia, es recomendable una mayor incorporación de aplicaciones 2.0, en los websites de las organizaciones sanitarias. Además de dotar a esas organizaciones de mayor visibilidad y transparencia, las herramientas Web 2.0 ofrecen un espacio público virtual donde desarrollar la comunicación entre usuarios, así como nuevos foros para deliberación, mejorar la discusión y promover un intercambio democrático de ideas y opiniones (Cmeciu y Cmeciu, 2014).

Destacaba también en este estudio, que las webs de la EP, CS, SAS y RSA, eran las que incorporaban un mayor número de herramientas para materializar la participación ciudadana, lo cual puede ser debido a que las funciones propias de estos organismos están relacionadas con la información y la interacción con la ciudadanía. Por el contrario, las webs de la ACSA y la EASP, incluían menor número de herramientas participativas, concretamente menos de la tercera parte de las propuestas en nuestro estudio. Creemos que este menor desarrollo de aplicaciones participativas tiene que ver también con la función propia de esos dos organismos, que les hacen relacionarse con un público más específico y minoritario, y por consiguiente desarrollan una menor relación con la ciudadanía en general.

Según el presente estudio, el nulo desarrollo que tuvieron las "aplicaciones on line para la interacción entre usuarios" (Tabla VIII), se debió a que en el SSPA no se hallaron aplicaciones participativas de debate, ni herramientas colaborativas para que múltiples usuarios puedan trabajar en red (Brodahl y otros, 2011). Indudablemente, esta carencia dificulta la interacción directa de la ciudadanía sobre la gestión sanitaria. Similares resultados a estos, obtienen trabajos sobre administraciones públicas locales (Moreno y otros,
2013), o sobre comunicación política (Casacuberta y Gutiérrez-Rubí, 2010), pues también esos autores observan un déficit de herramientas virtuales de participación y de interacción directa sobre la gestión política. Aunque el desarrollo de herramientas 2.0 no garantiza la participación de los usuarios (Tejedor-Calvo, 2010), con la no inclusión de estas herramientas de colaboración colectiva y descentralizada de la ciudadanía (Casacuberta y Gutiérrez-Rubí, 2010), no se tiende a desarrollar completamente los principios y filosofía de la Web 2.0, basada en la "colaboración, participación, retroalimentación, transparencia y democratización" (Salvador-Benítez y Gutiérrez-David, 2010).

También llama la atención que el parámetro "Publicación de contenidos creados por los usuarios" obtuviese un grado de desarrollo muy bajo, en las webs estudiadas (Tabla VIII). El escaso desarrollo de herramientas, para publicar contenidos de los usuarios en el ámbito sanitario, concuerda también con el bajo empleo de estas herramientas en otras instituciones públicas (Karkin, 2013; Moreno y otros, 2013). Esto no ocurre en los ciberdiarios, donde los contenidos creados por los usuarios tienen cada vez más presencia (Díaz del Campo, 2014; García-De-Torres, 2010; Ihlebæk y Krumsvik, 2015).

Este desarrollo tan bajo de las herramientas virtuales para crear contenidos ciudadanos en las seis webs del SSPA, se debió a que sólo la web de la EP posibilitaba la creación de blogs y la publicación de textos o videos realizados por usuarios, aunque tampoco poseía una sección específica en su website para publicar esos contenidos de los usuarios. Si la primera señal de apuesta por la Web 2.0, surge a principios de la década pasada, con la posibilidad de que en los cibermedios se puedan crear blogs de autor y zonas para la publicación de contenidos ciudadanos (García-De-Torres, 2010), los pobres 
resultados de nuestro estudio, en un sistema sanitario avanzado en participación ciudadana, pueden indicar que en el ámbito de las organizaciones sanitarias aún no existe una apuesta clara por las aplicaciones Web 2.0, como motor para materializar la participación ciudadana.

Esas escasas posibilidades actuales, de que los usuarios creen y publiquen contenidos en las webs estudiadas, puede ser debido a que el flujo informativo generado por los usuarios, que retorna a las organizaciones tiene valor, fundamentalmente, como fuente de compulsión o presión sobre la propia organización (García-de-Torres, 2010). A esto habría que sumar las posibles reticencias de las organizaciones, a perder el control sobre la información o sobre los procesos de toma de decisiones, si se posibilitara que los usuarios abordasen colectiva y públicamente los asuntos de salud mediante herramientas Web 2.0.

A pesar de que el desarrollo Web 2.0 abre paso al usuario activo productor de contenidos, parece que hay cierta resistencia en las organizaciones para emplear este tipo de herramientas colaborativas y generadoras de contenidos, ajenas al paradigma clásico. Por ello, futuros estudios deberían abordar la capacidad real de generar, usar o manipular el contenido de las webs de organizaciones sanitarias por los usuarios.

Según nuestra investigación, tampoco se implementó la posibilidad de que los usuarios de las webs del SSPA, modificasen o corrigiesen los contenidos publicados en esas webs, ni las consultas públicas a la ciudadanía en asuntos de salud, de interés general (Tabla V). Aunque la web de la EP usó una aplicación para preguntar a los usuarios, en nuestra evaluación no fue tenida en cuenta esta herramienta, dado que se consideró que la consulta pública no se realizaba sobre un asunto de salud de interés general. Esto demuestra que las organizaciones sanitarias están preparadas tecnológicamente para emplear aplicaciones Web 2.0, de relación entre web y usuarios, pero por causas que habría que averiguar deciden no emplearlas para consultar a la ciudadanía sobre cuestiones de salud.

Igualmente, en las webs estudiadas, apenas se explotaba la posibilidad de que los usuarios comentasen los contenidos publicados en las webs o pudiesen preguntar a las organizaciones sanitarias, y que éstas les respondiesen públicamente vía web. Esto denota que a diferencia de ámbitos como la política, donde se está generando un nuevo paradigma de comprensión de la participación ciudadana, basado en la Web 2.0 (Casacuberta y Gutiérrez-Rubí, 2010), en el ámbito sanitario perdura, en buena parte, un sistema vertical de comunicación en el que el ciudadano es básicamente usuario, consumidor y receptor pasivo de información, y la creación e interacción es mínima y limitada a momentos muy concretos.

Sin embargo, la presencia de las organizaciones del SSPA en las redes sociales y la existencia de aplicaciones Web 1.0 y 2.0 , para favorecer la información a la ciudadanía, fueron los parámetros estudiados más desarrollados, en las webs del SSPA, aunque sólo obtuvieron un grado de desarrollo medio (Tabla VIII). Respecto a la presencia del SSPA en redes sociales, destacó positivamente que excepto el SAS, las cinco restantes organizaciones estudiadas estuviesen presentes en estas comunidades sociales multimedia y de amistad. Igualmente, llamó la atención que ninguna de las organizaciones del SSPA tuviese presencia en redes sociales profesionales externas como LinkedIn o Xing (Tabla VII). Este interés del SSPA en estar presente en las redes sociales, puede relacionarse con que los "ciudadanos se han acostumbrado a esta forma de vida y a esta manera de comunicarse, a generar sus propios contenidos, a compartirlos y dialogar", a través de las comunidades sociales (Casacuberta y Gutiérrez-Rubí, 2010). Esto también concuerda con estudios recientes, que delatan el crecimiento de los medios sociales y blogs como plataformas usadas para la participación y deliberación, por un amplio espectro de ciudadanos (Ihlebæk y Krumsvik, 2015).

A la vista de todo lo anterior, parece que las organizaciones sanitarias también deberían "realizar cambios en sus planteamientos tradicionales, incorporando en clave colaborativa los tres pilares de los social media: contenidos generados por el usuario, comunidades y la Web 2.0 (Salvador-Benítez y Gutiérrez-David, 2010). Con estos nuevos recursos tecnológicos se dinamizarían los actuales procesos participativos en asuntos de salud, consiguiendo una mayor participación, dado que los nuevos procesos virtuales se sumarían a los procesos participativos presenciales ya existentes. Así, cada persona interesada tendría más posibilidades de expresarse y participar, individual o colectivamente, en asuntos públicos de salud.

\section{CONCLUSIONES}

En nuestro estudio se identificaron y propusieron 42 herramientas para materializar, a través de las webs de organizaciones sanitarias, la participación ciudadana virtual, en el ámbito de la salud. Esta propuesta superó cuantitativa y cualitativamente a las herramientas participativas manejadas por otros autores y ámbitos. 
Las herramientas propuestas, agrupadas en seis parámetros, desarrollan todos los ámbitos que materializan la participación ciudadana virtual en salud, siendo estos, la elaboración de contenidos para la promoción de la salud de la ciudadanía; herramientas 2.0 de interacción web-usuarios; publicación de contenidos creados por los usuarios; presencia en redes sociales y aplicaciones para la interacción, diálogo y colaboración entre usuarios.

Casi el $80 \%$ de las 42 herramientas identificadas para materializar la participación ciudadana, están presentes en las seis webs analizadas del Sistema Sanitario Público Andaluz, lo cual denota la toma de conciencia y propósito de ese organismo sanitario, para adaptarse a nuevos entornos web, más participativos e interactivos con la ciudadanía.

La presencia de las organizaciones del Sistema Sanitario Público Andaluz en redes sociales, así como las aplicaciones Web 2.0 y 1.0 para informar

\section{REFERENCIAS}

Brodahl, C; Hadjerrouit, S.; Hansen, N.K. (2011). Collaborative Writing with Web 2.0 Technologies: Education Students' Perceptions. Journal of Information Technology Education: Innovations in Practice, vol. 10, 73-110.

Calvo-Calvo, M.A. (2014). Calidad y características de los sitios web de los hospitales españoles de gran tamaño. Revista Española de Documentación Científica, vol. 37 (1), e032. http://dx.doi. org/10.3989/redc.2014.1.1049

Casacuberta, D.; Gutiérrez-Rubí, A. (2010). e-Participación: de cómo las nuevas tecnologías están transformando la participación ciudadana. Razón y Palabra, 73.

Checa, F. (2013). El uso de podcast y wikis como herramientas de generación y gestión de conocimiento. Nómadas. Revista Crítica de Ciencias Sociales y Jurídicas, vol. 40 (4), 113-137. http:// dx.doi.org/10.5209/rev_NOMA.2013.v40.n4.48339

Cmeciu, C.; Cmeciu, D. (2014). Web 2.0 communication and stakeholder engagement strategies: how Romanian public organizations use Facebook. Procedia - Social and Behavioral Sciences, vol. 143, 879-883. http://dx.doi.org/10.1016/j. sbspro.2014.07.510

Díaz-Campo, J. (2014). Interactividad y participación en las páginas web de los principales diarios deportivos españoles. Revista de Comunicación Vivat Academia, no 127, 1-18. http://dx.doi. org/10.15178/va.2014.127.1-18 a la ciudadanía, fueron los recursos participativos más desarrollados en las webs de ese sistema sanitario, aunque sólo alcanzaron un grado medio de desarrollo. Sin embargo, las herramientas 2.0 para la interacción web-usuarios y para la publicación de contenidos creados por los usuarios, tuvieron un bajo y muy bajo grado de desarrollo respectivamente, en las webs estudiadas. Ese desarrollo fue nulo, en el caso de las aplicaciones on line para la interacción y colaboración entre usuarios.

Al igual que otros ámbitos públicos, las organizaciones sanitarias deben modificar sus planteamientos tradicionales e incorporar herramientas virtuales en clave colaborativa que ofrezcan a las personas la oportunidad de generar contenidos, compartirlos y dialogar entre ellos, en el marco de las nuevas comunidades sociales Web 2.0, y así materializar la participación y contribución ciudadana al ámbito de la salud.

García-De-Torres, E. (2010). Contenido generado por el usuario: aproximación al estado de la cuestión. El profesional de la información, vol. 19 (6), 585594. http://dx.doi.org/10.3145/epi.2010.nov.04

Haneefa, K.; Jasna, K. (2014). Web applications in online newspaper: A content analysis. Annals of Library and Information Studies, vol. 61, 307-319.

Ihlebæk, K.A.; Krumsvik, A.H. (2015). Editorial power and public participation in online newspapers. Journalism, vol. 16 (4), 470-487. http://dx.doi. org/10.1177/1464884913520200

Instituto Nacional de Estadística. (2015). Cifras de Población a 1 de enero de 2015. Madrid: Ministerio de Economía y Competitividad, del Gobierno de España. http://www.ine.es/prensa/np917.pdf [10 de noviembre de 2015]

Jovell, A.J.; Navarro, M.D. (2008). La voz de los pacientes ha de ser escuchada. Informe SESPA 2008. Gaceta Sanitaria, vol. 22 (Supl 1), 192-197. http://dx.doi.org/10.1016/S0213-9111(08)76092-8

Karkin, N. (2013). Herramientas Web 2.0 para la participación pública a través de los sitios de Internet del gobierno. Gestión y Política Pública, volumen temático 2013, 307-331.

Kolasa, K.; Dohnalik, J.; Borek, E.; Siemiątkowski, M.; Ścibiorski, C. (2014). The paradox of public participation in the healthcare in Poland - What citizens want, and what they think. Health Policy, vol. 118 (2), 159-165. http://dx.doi.org/10.1016/j.healthpol.2014.09.015 
Márquez, J.M.; Vázquez, R.; Martínez, M.; Roldán, N. (2013). Estudio de la Demanda y uso de Gobierno Abierto en España. Madrid: Observatorio Nacional de las Telecomunicaciones y de la Sociedad de la Información. http://www.ontsi.red.es/ontsi/sites/ ontsi/files/demanda_y_uso_de_gobierno_abierto_ en_espana.pdf [6 de noviembre de 2015].

Martín, A.; Pérez, O.; Iriarte, T.; Gómez, M.E. (2013). Guía metodológica para la elaboración/ actualización del Plan de Participación de Hospitales, Distritos y Áreas Sanitarias. Sevilla: Consejería de Igualdad, Salud y Políticas Sociales de la Junta de Andalucía. http://www.juntadeandalucia.es/ servicioandaluzdesalud/library/plantillas/externa. asp?pag=/contenidos/gestioncalidad/gestionclinica/ Guia_centro.pdf [1 de noviembre de 2015].

Moreno, A.; Molina, P.; Corcoy, M. (2013). La información de las administraciones públicas locales. Las webs de los ayuntamientos de Cataluña. Revista Latina de Comunicación Social, 68, 502-528.

Navarro, M.D. (2014). Pacientes implicados: participación del paciente en la toma de decisiones. Papeles de Economía Española, no 142, 85-91.

Novo, A.; Vicente, M.R. (2014). Participo (online), luego existo. Un análisis de la participación social y política a través de Internet en España. Empiria. Revista de Metodología en Ciencias Sociales, no 38, 13-34.

Perestelo-Pérez, L.; Jeanette Pérez-Ramos, J.; AbtSacks, A.; Amado Rivero-Santana, A.; SerranoAguilar, P. (2013). Promoción de la participación ciudadana en cuidados de salud a través de PyDEsalud. com. Gaceta Sanitaria, vol. 27 (5), 466-467. http:// dx.doi.org/10.1016/j.gaceta.2013.01.007

Pérez, E.; Campos, R.; Campos, G.E. (2014). Etiquetado social: un modelo de representación de la información en la blogosfera. Biblios (online), 56, 19-27. http://dx.doi.org/10.5195/biblios.2014.187
Rodríguez-Martínez, R.; Codina, L.; Pedraza-Jiménez, R. (2012). Indicadores para la evaluación de la calidad en cibermedios: análisis de la interacción y de la adopción de la Web 2.0. Revista Española de Documentación Científica, vol. 35 (1), 61-93. http://dx.doi.org/10.3989/redc.2012.1.858

Ruiz, C; Monsalve, R.A.; Diego, A; Mazorra, C. (2012). Participación política: comunidad LGBTI en la Web 2.0. Comunicación y Ciudadanía, 5, 98-109.

Salvador-Benítez, A.; Gutiérrez-David, M.A. (2010). Redes sociales, 2.0 y medios de comunicación: desafíos legales. El profesional de la información, vol. 19(6), 667-674. http://dx.doi.org/10.3145/ epi.2010.nov.14

Santana, F.; Stralen, C.J.; Antunes, P.H. (2014). Participação social e saúde no Brasil: revisão sistemática sobre o tema. Ciência \& Saúde Coletiva, vol. 19 (2), 487-498. http://dx.doi. org/10.1590/1413-81232014192.10542012.

Segura, A. (2010). La participación ciudadana, la sanidad y la salud. Gestión Clínica y Sanitaria, vol. $12(2), 55-62$.

Serapioni, M.; Matos, A.R. (2014). Citizen participation and discontent in three Southern European health systems, Social Science \& Medicine, vol. 123, 226-233. http://dx.doi.org/10.1016/j. socscimed.2014.06.006

Tejada, B. (2012). Herramientas de la Web 2.0 aplicadas al estudio. $V$ Congreso Mundial de Estilos de Aprendizaje. Santander, España. http://dialnet. unirioja.es/servlet/articulo?codigo $=4648094 \quad[11$ de noviembre de 2015]

Tejedor-Calvo, S. (2010). Web 2.0 en los ciberdiarios de América Latina, España y Portugal, El profesional de la información, 19 (6), 610-619. http://dx.doi. org/10.3145/epi.2010.nov.07 


\section{Anexo I}

\section{Herramientas y contenidos de las webs que facilitan la participación ciudadana en asuntos de salud}

\begin{tabular}{|c|c|c|}
\hline Herramientas & Descripción & n* \\
\hline $\begin{array}{l}\text { 1.1. Sección de "Participación } \\
\text { ciudadana" }\end{array}$ & $\begin{array}{l}\text { En la website existe una sección de "Participación ciudadana" o } \\
\text { "Ciudadanía". }\end{array}$ & 2 \\
\hline $\begin{array}{l}\text { 1.2. Información sobre el plan } \\
\text { de participación ciudadana }\end{array}$ & $\begin{array}{l}\text { Se ofrece en la web, información sobre el plan o programa de participación } \\
\text { ciudadana }\end{array}$ & 1 \\
\hline $\begin{array}{l}\text { 1.3. Agenda de actividades para } \\
\text { la ciudadanía }\end{array}$ & $\begin{array}{l}\text { Se ofrece en la web, la agenda de actividades organizadas y dirigidas a los } \\
\text { usuario (cursos, congresos,...) }\end{array}$ & 1 \\
\hline $\begin{array}{l}\text { 1.4. Enlaces a webs de } \\
\text { entidades ciudadanas }\end{array}$ & $\begin{array}{l}\text { Existen enlaces a webs de salud, pertenecientes a entidades ciudadanas, } \\
\text { voluntarios, de usuarios, grupos de pacientes, etc. }\end{array}$ & 2 \\
\hline $\begin{array}{l}\text { 1.5. Información sobre listas de } \\
\text { espera }\end{array}$ & Información sobre listas de espera quirúrgicas, consultas, etc. & 2 \\
\hline $\begin{array}{l}\text { 1.6. Contenidos sobre } \\
\text { información y promoción de la } \\
\text { salud }\end{array}$ & $\begin{array}{l}\text { Existen espacios en la web con consejos de salud, información sobre } \\
\text { enfermedades y temas de educación y promoción de la salud, dirigidos a la } \\
\text { ciudadanía, en formato texto o multimedia. }\end{array}$ & 3 \\
\hline $\begin{array}{l}\text { 1.7. Sección de noticias de } \\
\text { actualidad }\end{array}$ & Hay sección de noticias de actualidad e interés sobre temas de salud. & 5 \\
\hline $\begin{array}{l}\text { 1.8. Publicación de resultados } \\
\text { de la encuesta de satisfacción }\end{array}$ & $\begin{array}{l}\text { Se publican datos de los resultados de encuestas de satisfacción de los } \\
\text { usuarios sobre los servicios sanitarios }\end{array}$ & 1 \\
\hline \multicolumn{2}{|c|}{ n*=número de veces que aparecen las herramientas del parámetro, en las webs estudiadas del SSPA. } & 17 \\
\hline \multicolumn{3}{|c|}{ Parámetro 2. Aplicaciones Web 2.0 para la información, educación y promoción de la salud de la ciudadanía } \\
\hline Herramientas & Descripción & n* \\
\hline $\begin{array}{l}\text { 2.1. Contenidos recomendados } \\
\text { por los usuarios ("Más popular") }\end{array}$ & $\begin{array}{l}\text { El website tiene una sección en la que el usuario puede conocer y accede } \\
\text { a aquellos contenidos que han tenido un mayor impacto entre los usuarios } \\
\text { (información más leídas, las más buscadas, las más vistas, las más } \\
\text { enviadas por los usuarios, etc.). }\end{array}$ & 0 \\
\hline $\begin{array}{l}\text { 2.2. Enlaces RSS (Servicios de } \\
\text { sindicación de contenidos) }\end{array}$ & $\begin{array}{l}\text { La web proporciona enlaces RSS y los usuarios pueden subscribirse a } \\
\text { esos enlaces para recibir información publicada en esa web, sobre los } \\
\text { temas que sean de interés del usuario, en sus propias plataformas (correo } \\
\text { electrónico, weblogs, redes sociales, página de iGoogle, teléfono móvil, } \\
\text { etc.). }\end{array}$ & 4 \\
\hline $\begin{array}{l}\text { 2.3. Suscripción de alertas o } \\
\text { boletín electrónico }\end{array}$ & $\begin{array}{l}\text { El usuario tiene la opción de suscribirse al servicio de alertas o boletín } \\
\text { electrónico del sitio web para recibir por correo electrónico, móvil, etc., } \\
\text { aquella información que la web publique sobre la temática que le interese. }\end{array}$ & 2 \\
\hline $\begin{array}{l}\text { 2.4. Compartir información con } \\
\text { otros usuarios }\end{array}$ & $\begin{array}{l}\text { La web permite al usuario compartir aquellas informaciones que resulten } \\
\text { de su interés con otros usuarios, utilizando herramientas propias de la } \\
\text { Web 2.0: redes sociales de amistades o profesionales, como Facebook o } \\
\text { LinkedIn, sitios webs tipo Menéame, Delicious, MySpace, Technorati, MSN } \\
\text { Reporter, Google Bookmarks, Twitter, etc. }\end{array}$ & 4 \\
\hline $\begin{array}{l}2.5 \text {. Blogs vinculados a la web } \\
\text { y creados por profesionales del } \\
\text { Sistema Sanitario }\end{array}$ & $\begin{array}{l}\text { En el sitio web del Servicio de Salud hay blogs (fotoblogs, audioblogs, } \\
\text { videoblogs, etc.) creados por profesionales o colaboradores del Servicio de } \\
\text { Salud. }\end{array}$ & 1 \\
\hline 2.6. Podcasts o videocasts & $\begin{array}{l}\text { En la web del Servicio de Salud hay posibilidad de escuchar las emisiones } \\
\text { de audio o ver los videos, tras descargarlos, donde quisiera y en el } \\
\text { momento en que quisiera. }\end{array}$ & 3 \\
\hline 2.7. Tags o etiquetas sociales & $\begin{array}{l}\text { En la website existe posibilidad de recopilar información y objetos digitales } \\
\text { mediante búsqueda con tags o etiquetas, que construyen los usuarios } \\
\text { con un lenguaje común, para organizar o clasificar los contenidos en } \\
\text { categorías. }\end{array}$ & 2 \\
\hline \multicolumn{2}{|c|}{ n*=número de veces que aparecen las herramientas del parámetro, en las webs estudiadas del SSPA. } & 16 \\
\hline
\end{tabular}




\begin{tabular}{|c|c|c|}
\hline \multicolumn{3}{|c|}{$\begin{array}{l}\text { Parámetro 3. Herramientas de interacción web-usuarios } \\
\text { Aplicaciones de las webs que facilitan la participación activa de los usuarios }\end{array}$} \\
\hline Herramientas & Descripción & n* \\
\hline $\begin{array}{l}\text { 3.1. Comunicación con el autor } \\
\text { de los contenidos de la web }\end{array}$ & $\begin{array}{l}\text { Posibilidad de que los ciudadanos contacten, a través del correo electrónico } \\
\text { o formulario web, con el autor de la información o contenido publicado en } \\
\text { la web, para solicitar información adicional o expresar opinión, sobre el } \\
\text { contenido publicado, etc. }\end{array}$ & 2 \\
\hline $\begin{array}{l}\text { 3.2. Contacto con el } \\
\text { administrador o responsable del } \\
\text { website }\end{array}$ & $\begin{array}{l}\text { Se facilita al usuario la opción de contactar con el administrador o } \\
\text { responsable de la web, o de alguna sección, a través del correo electrónico } \\
\text { o de formularios. }\end{array}$ & 5 \\
\hline $\begin{array}{l}\text { 3.3. Comentar contenidos } \\
\text { publicados en la web }\end{array}$ & $\begin{array}{l}\text { Mediante formularios o email, se permite al usuario realizar comentarios } \\
\text { sobre la información y contenido de la web, se publican dichos comentarios } \\
\text { y también se pueden ver los comentarios de otros usuarios. }\end{array}$ & 2 \\
\hline $\begin{array}{l}\text { 3.4. Comentar entradas } \\
\text { publicadas en blogs vinculados } \\
\text { a la web }\end{array}$ & $\begin{array}{l}\text { Posibilidad de que los usuarios comenten entradas publicadas en los blogs } \\
\text { vinculados a la web. }\end{array}$ & 1 \\
\hline $\begin{array}{l}\text { 3.5. Valoración de los usuarios, } \\
\text { sobre los contenidos del website }\end{array}$ & $\begin{array}{l}\text { El usuario puede valorar mediante votación anónima, los contenidos } \\
\text { que publica la web para conocer si éstos han sido o no de su interés, } \\
\text { para mostrar su satisfacción o insatisfacción sobre el tratamiento de la } \\
\text { información y contenidos publicados. Se publica el resultado total de las } \\
\text { votaciones realizadas por los usuarios. }\end{array}$ & 3 \\
\hline $\begin{array}{l}\text { 3.6. Modificación por los } \\
\text { usuarios, del contenido } \\
\text { publicado en la web }\end{array}$ & $\begin{array}{l}\text { El usuario, mediante email o formulario web, puede proponer a los autores } \\
\text { modificaciones o correcciones de información y contenidos publicados en el } \\
\text { website, que puedan ser mejorados o requieran ser modificados. }\end{array}$ & 0 \\
\hline $\begin{array}{l}\text { 3.7. Solicitud de información } \\
\text { general y sobre los servicios del } \\
\text { sistema sanitario }\end{array}$ & $\begin{array}{l}\text { Existe posibilidad de que a través de la web, la ciudadanía pueda realizar } \\
\text { consultas o solicitud de información general y específica, mediante email o } \\
\text { formulario, sobre los servicios del sistema sanitario. }\end{array}$ & 2 \\
\hline $\begin{array}{l}\text { 3.8. Espacio público para } \\
\text { preguntas y respuestas de los } \\
\text { ciudadanos (b) }\end{array}$ & $\begin{array}{l}\text { Existe en la web, espacio de acceso abierto para las preguntas realizadas } \\
\text { por los usuarios al Servicio de Salud, incluyendo también las respuestas } \\
\text { correspondientes, dadas por los responsables de la web. }\end{array}$ & 1 \\
\hline $\begin{array}{l}\text { 3.9. Buzón electrónico de } \\
\text { sugerencias }\end{array}$ & $\begin{array}{l}\text { Hay herramientas en la web para que el ciudadano comunique al Servicio } \\
\text { de Salud, incidencias, quejas, sugerencias, etc., mediante email o } \\
\text { formularios. }\end{array}$ & 3 \\
\hline $\begin{array}{l}\text { 3.10. Consultas públicas a la } \\
\text { ciudadanía sobre asuntos de } \\
\text { salud de interés }\end{array}$ & $\begin{array}{l}\text { Desde las webs se realizan consultas públicas virtuales, mediante } \\
\text { encuestas a la ciudadanía, sobre asuntos de salud de interés para la } \\
\text { administración sanitaria o usuarios. }\end{array}$ & 0 \\
\hline $\begin{array}{l}\text { 3.11. Posibilidad de pedir cita } \\
\text { para consultas médicas a través } \\
\text { de la web }\end{array}$ & $\begin{array}{l}\text { En la web del Servicio de Salud, hay una aplicación para pedir cita para } \\
\text { consultas médicas de Atención Primaria y de Atención Especializada. }\end{array}$ & 2 \\
\hline $\begin{array}{l}\text { 3.12. Registro por parte del } \\
\text { usuario en el website }\end{array}$ & $\begin{array}{l}\text { El website ofrece a los usuarios la posibilidad de registrarse para que éste } \\
\text { los identifique y puedan comentar, recomendar y votar los contenidos, y } \\
\text { enviar material a la web para que esta lo publique, etc. }\end{array}$ & 3 \\
\hline $\begin{array}{l}\text { 3.13. Contacto con otros } \\
\text { usuarios registrados }\end{array}$ & $\begin{array}{l}\text { La web ofrece la posibilidad de que los usuarios registrados puedan } \\
\text { interactuar y comunicarse entre sí. }\end{array}$ & 0 \\
\hline \multicolumn{2}{|c|}{$\mathrm{n}^{*}=$ número de veces que aparecen las herramientas del parámetro, en las webs estudiadas del SSPA. } & 24 \\
\hline \multicolumn{3}{|c|}{ Parámetro 4. Publicación de contenidos creados por los usuarios } \\
\hline Herramientas & Descripción & n* \\
\hline $\begin{array}{l}\text { 4.1. Creación de blogs por } \\
\text { usuarios del website }\end{array}$ & $\begin{array}{l}\text { En el sitio web del Sistema Sanitario hay blogs (fotoblogs, audioblogs, } \\
\text { videoblogs, etc.) creados por usuarios, con posibilidad de que otros } \\
\text { usuarios comenten las "entradas". Los ciudadanos pueden escribir sobre } \\
\text { temas elegidos por ellos. }\end{array}$ & 1 \\
\hline $\begin{array}{l}\text { 4.2. Publicación de textos } \\
\text { escritos por los usuarios }\end{array}$ & $\begin{array}{l}\text { La web del Servicio de Salud publica textos generados y enviados por los } \\
\text { usuarios }\end{array}$ & 1 \\
\hline $\begin{array}{l}\text { 4.3. Publicación de fotos } \\
\text { tomadas por los usuarios }\end{array}$ & $\begin{array}{l}\text { La web permite que los usuarios envíen fotos para que sean publicadas en } \\
\text { su sitio web. }\end{array}$ & 0 \\
\hline $\begin{array}{l}\text { 4.4. Publicación de vídeos } \\
\text { realizados por los usuarios }\end{array}$ & $\begin{array}{l}\text { Los usuarios tienen la posibilidad de enviar vídeos para que éstos sean } \\
\text { publicados en el sitio web. }\end{array}$ & 1 \\
\hline
\end{tabular}




\begin{tabular}{|c|c|c|}
\hline $\begin{array}{l}\text { 4.5. Publicación de contenidos } \\
\text { de los usuarios, en sección } \\
\text { específica }\end{array}$ & $\begin{array}{l}\text { Existe en la web una sección o espacio exclusivo para publicar el contenido } \\
\text { creado por los usuarios. }\end{array}$ & 0 \\
\hline \multicolumn{2}{|c|}{ n*=número de veces que aparecen las herramientas del parámetro, en las webs estudiadas del SSPA. } & 3 \\
\hline \multicolumn{3}{|c|}{$\begin{array}{l}\text { Parámetro 5. Presencia del Sistema Sanitario en plataformas de la Web } 2.0 \text { (redes sociales) } \\
\text { El Servicio de Salud posee espacios en plataformas de la Web } 2.0 \text {, que no se dedican exclusivamente a cuestiones de } \\
\text { naturaleza sanitaria, para difundir la información que produce entre los usuarios de dichas plataformas. }\end{array}$} \\
\hline Herramientas & Descripción & n* \\
\hline $\begin{array}{l}\text { 5.1. Presencia en plataformas } \\
\text { Audiovisuales }\end{array}$ & $\begin{array}{l}\text { El Sistema Sanitario está presente en plataformas de la Web } 2.0 \\
\text { especializadas en la difusión de vídeos para canalizar el material } \\
\text { audiovisual que produce, como Youtube, Vimeo, etc. }\end{array}$ & 3 \\
\hline $\begin{array}{l}\text { 5.2. Presencia en plataformas } \\
\text { de imágenes }\end{array}$ & $\begin{array}{l}\text { El Sistema Sanitario está presente en plataformas de la Web } 2.0 \\
\text { especializadas en la difusión de material fotográfico e imágenes para } \\
\text { difundir su material fotográfico que produce, como Flickr u otras. }\end{array}$ & 1 \\
\hline $\begin{array}{l}\text { 5.3. Presencia en redes sociales } \\
\text { profesionales externas }\end{array}$ & $\begin{array}{l}\text { El Sistema Sanitario atrae y fideliza usuarios a través de los sitios webs de } \\
\text { redes sociales profesionales más populares en el entorno de la Web } 2.0 \text {, } \\
\text { como son LinkedIn o Xing }\end{array}$ & 0 \\
\hline $\begin{array}{l}\text { 5.4. Presencia en redes sociales } \\
\text { de amistad }\end{array}$ & $\begin{array}{l}\text { El Sistema Sanitario atrae y fideliza usuarios haciendo uso de las redes } \\
\text { sociales de amistad que cuentan con mayor popularidad, como Facebook. }\end{array}$ & 4 \\
\hline $\begin{array}{l}\text { 5.5. Presencia en plataformas } \\
\text { de microblogging }\end{array}$ & $\begin{array}{l}\text { El Sistema Sanitario hace uso de plataformas de microblogging con un } \\
\text { gran número de usuarios registrados, como Twitter, para difundir la } \\
\text { información que produce entre los usuarios de dichos sitios web. }\end{array}$ & 5 \\
\hline $\begin{array}{l}\text { 5.6. Otras redes sociales en las } \\
\text { que está presente el Sistema } \\
\text { Sanitario }\end{array}$ & Slideshare, MySpace, Orkut, Hi5, otras. & 2 \\
\hline $\begin{array}{l}\text { 5.7. Enlaces entre el sitio web y } \\
\text { las plataformas sociales (c) }\end{array}$ & $\begin{array}{l}\text { La web incorpora iconos clicables para informar a sus usuarios de su } \\
\text { presencia en plataformas sociales. }\end{array}$ & 5 \\
\hline \multicolumn{2}{|c|}{$\mathrm{n}^{*}=$ número de veces que aparecen las herramientas del parámetro, en las webs estudiadas del SSPA. } & 20 \\
\hline \multicolumn{3}{|c|}{$\begin{array}{l}\text { Parámetro 6. Aplicaciones on line para la interacción entre usuarios } \\
\text { Herramientas Web } 2.0 \text { para la participación y colaboración activa de los usuarios y toma de decisiones colectivas }\end{array}$} \\
\hline Herramientas & Descripción & n* \\
\hline $\begin{array}{l}\text { 6.1. Aplicaciones participativas } \\
\text { de debate }\end{array}$ & $\begin{array}{l}\text { Existen aplicaciones participativas de debate, foros electrónicos virtuales } \\
\text { (grupos de discusión on line), chats (cibercharla), grupos de noticias, } \\
\text { tablones de anuncios, grupos de discusión, listas de distribución, } \\
\text { mensajería instantánea, etc., con la posibilidad de crear grupos por los } \\
\text { usuarios. }\end{array}$ & 0 \\
\hline $\begin{array}{l}\text { 6.2. Herramientas digitales } \\
\text { colaborativas de participación } \\
\text { online }\end{array}$ & $\begin{array}{l}\text { Existen herramientas digitales colaborativas, que permiten trabajar en red, } \\
\text { en colaboración con muchas personas. } \\
\text { 1. Herramientas colaborativas de escritura: Wikis; Titanpad; Co-ment; } \\
\text { Google Docs; EtherPad } \\
\text { 2. Herramientas de toma de decisiones (debate y votación): Appgree, } \\
\text { Liquidfeedback, Agora voting, Loomio,... } \\
\text { 3. Herramientas de recopilación y selección de contenidos: Menéame, } \\
\text { Reddit,.. } \\
\text { 4. Otras herramientas de participación online/colaborativas para trabajar } \\
\text { en red }\end{array}$ & 0 \\
\hline \multicolumn{2}{|c|}{ n*=número de veces que aparecen las herramientas del parámetro, en las webs estudiadas del SSPA. } & 0 \\
\hline
\end{tabular}

